\title{
Intelligent Tutoring and Training Tools for the Electric Power Sector Developed at IIE
}

\author{
Alberto Reyes, Yasmín Hernández, Pablo de Buen, Eduardo Islas, Miguel \\ Pérez, Carlos F. García-Hernández, Guillermo Rodríguez, Rogelio Martínez, \\ and Fernando Jiménez \\ \{areyes, myhp, debuen, eislas, mperez, cfgarcia, gro, remr,fjimenez\}@iie.org.mx \\ http://www.iie.org.mx
}

\begin{abstract}
The electric power industry requires qualified personnel to support an optimal and safe operation. Since its beginnings, the IIE has been developing different training technologies and systems for CFE, the main utility for generation, transmission and distribution of electric power in Mexico. Some of these endeavors provide tailored instruction considering trainees traits such as learning styles, affective states and current knowledge. Other developments are focused on enabling multifunctionality. The IIE has also developed intelligent assistant systems, virtual reality systems, and power plant simulators. Besides this, the IIE is interested in developing e-learning platforms to support CFE's personnel training. This paper presents a summary of these developments.
\end{abstract}

Keywords: Adaptive instruction, intelligent assistants, virtual reality systems, training simulators, learning environments.

\section{Introduction}

The Electrical Research Institute (IIE) is a public institution dedicated to innovation, technological development and applied scientific research, within the electrical and oil industries, and one of its main functions is to support the Federal Electricity Commission's (CFE) processes. These processes are complex and involve different levels of risk. Thus, one of its main concerns is to make sure that its personnel is well trained and qualified in order to prevent accidents and equipment damage, as well as to reduce operational costs. Traditionally, personnel training was achieved by attending specialized courses. However, nowadays the industrial development demands opportune and flexible training. The IIE has developed different tools and training approaches, based on modern technologies, to support these challenges.

This paper describes some of the training tools developed by IIE. First, it presents two works focused on the importance of providing tailored instruction. These consider both learning styles theory and the student affective state. Then, it describes three multi-functionality systems namely: an intelligent assistant in the power plant domain, an adaptive system for learning and consulting engineering procedures, and an assistant system for the design of electrical distribution 
substations. After that, it explains the architecture followed by different systems based on virtual reality, one devoted specifically to live line maintenance training in different tensions, and other for the fossil fuel power plant domain. Later on, it talks about a power plant simulator complemented with an expert system for training of power plants operators. Then, it describes an e-learning platform constructed by the IIE. Finally, some conclusions are presented.

\section{Strategies for Adaptive Instruction}

\subsection{Learning Styles for Intelligent Learning Environments}

Until now, most of the intelligent learning environments personalize instruction basically by tracking what a student knows. However, adapting instruction is not only concerned with students current knowledge; there are many other proposals to adapt the lessons to other aspects of students like skills mastery, motivational and affective state, self-efficacy, learning styles, among other proposals. We have developed a general framework to adapt the instruction based on the FelderSilverman Learning Styles Model [1]; the instruction is presented according to a set of rules taking into account the student's learning style which is identified by an assessment instrument given to students [2].

The learning styles theory relies on the hypothesis where each individual has a particular way to learn, including strategies and preferences, emphasizing that individuals perceive and process information in different ways. Consequently, the learning styles theory states that individuals learning has more to do with a process focusing on the learning style than with the individuals intelligence.

The Felder-Silverman categorizations of learning styles are: Active and reflective learners. The active learner better understands information by doing something with it and it likes group work. The reflective learner understands information better by thinking about it quietly first and it prefers to work alone. Other categorizations consider the existance of sensing and intuitive learners, visual and verbal learners, and sequential and global learners.

The sensing learner likes learning facts and solving problems by using wellestablished methods, but it dislikes complications. The intuitive learner prefers discovering possibilities and relationships and likes innovation but dislikes repetition. The visual learner remembers better what he/she sees: pictures, diagrams, flow charts, time lines, films, or demonstrations. The verbal one gets more from words and written and spoken explanations. The sequential gains understanding in linear steps and follows logical stepwise paths in finding solutions. The global one learns in large jumps and solves complex problems quickly once they have grasped the big picture.

To identify the learning style of a person, we use the Felder-Silverman assessment instrument, which is a Soloman and Felder questionnaire with 44 questions [3]. The collection of rules proposes a set of teaching instructions for each learning style [4]. Table 1 shows rules for active/reflective learners.

To apply these rules, every lesson of a course has to be converted into 8 different lessons according to the teaching instructions. This effort is justified 
Table 1. Rules of teaching instructions for active and reflective learning styles

\begin{tabular}{ll}
\hline Learning style & Teaching instructions \\
\hline Active & $\begin{array}{l}\text { Show exercises at the beginning of the chapter because they like challenges } \\
\text { and problem solving }\end{array}$ \\
& $\begin{array}{l}\text { Show less examples. They are not interested in the way others have done } \\
\text { something, because they want to solve a problem by themselves }\end{array}$ \\
\hline Reflective & $\begin{array}{l}\text { Show exercises at the end of a chapter } \\
\text { Show examples after explanation content, but before exercises } \\
\text { Show less exercises, because they learn better by thinking about a topic } \\
\text { instead of solving problems actively. }\end{array}$ \\
\end{tabular}

when there are many potential students classified in each of the learning styles so that they can better profit personalized learning objects.

To develop our proposal, we have assembled a site using Moodle with instructional material composed of lessons, tests, and exams in compliance with the SCORM standard (Shareable Content Object Reference Model). Currently, we are basing our proposal on an algorithm rooted in artificial intelligent planning techniques. In this way, an individual course is generated for each student based on his/her individual needs and his/her learning goals.

\subsection{A Model of Affective Behavior}

Emotions have been recognized as an important component of motivation and learning. There is support that experienced human tutors look at and react to the emotional state of students in order to motivate them and improve their learning process. In the few past years, there has been extensive work on modeling student emotions; however, there have been only limited attempts to integrate information on student affect in the tutorial decisions. To tackle this problem, we have developed an Affective Behavior Model (ABM).

The ABM takes affect into account when interacting with a student by inferring the affective state of the student; and by establishing the optimal tutorial action based on the students current affective state (besides knowledge). A diagram of the ABM is presented in Fig. 1. The model is composed of an affective student model and an affective tutor model. The tutor model produces an affective action considering the affective and pedagogical student models as well as the tutorial situation. The affective action is a component of the tutorial action to be presented to the student.

The affective student model is based on the OCC model of emotions [5], and relies on a Bayesian network [6]. The OCC model considers emotions as a result of a cognitive appraisal between situation and individual goals. In our model, goals are inferred based on the Five-Factor personality model [7].

The affective tutor model is designed based on interviews and surveys with 20 qualified teachers aimed at understanding which actions the teachers select according to the state of a students affect and knowledge. We asked them to say what they do when they are teaching. The teachers watched videos of students 


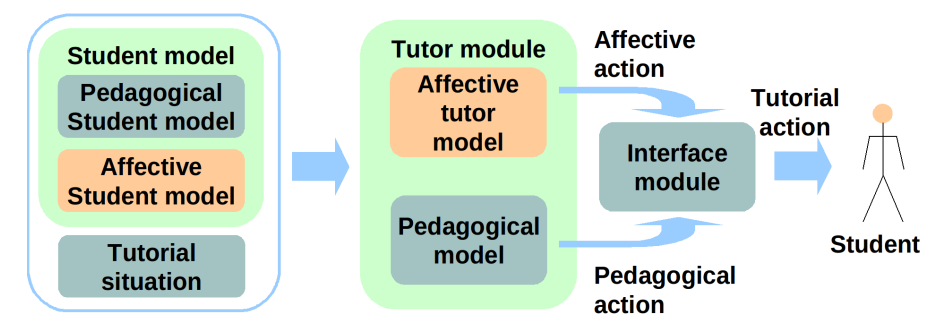

Fig. 1. General diagram for the Affective Behavior Model. The model is composed of an affective student model and an affective tutor model.

and they established the suitable affective and pedagogical actions for each tutorial situation, and they stated why they do those actions. The affective tutor model selects the tutorial actions with the best expected effect on a students affect and knowledge by using a dynamic decision network with a utility measure on both, learning and affect [8].

The ABM was tested in a controlled user study and in a wizard-of-oz study; 82 students participated. In both studies the tutorial action was delivered by an animated agent. The results of these studies are encouraging, since they show a high precision in the affective student model comparing with self-reports and they show positive impact on students learning comparing pre-tests with posttests.

\section{Multi-functional Intelligent Assistants}

\subsection{ASISTO: An Intelligent Assistant System for Power Plant Operators Training}

ASISTO (standing for Operation ASSISTant in Spanish) [9] is an intelligent assistant system composed of a training module that includes an instructor console conected to a plant simulator. The main component of the training mode is the explanation system which is aimed to provide new operators with background information during a training session. The automatic generation explanation mechanism is composed of two main stages. In the first stage, the most relevant variable is obtained by analyzing a Markov decision process (MDP)[10] used by the operation assistant. This relevant variable is defined as the factor that has the greatest impact on the utility given certain plant state and recommendation, and it represents a key element in the explanation generation mechanism. In the second stage, an explanation is generated by combining the information obtained from the MDP analysis, and displayed in the form of a general template. The current state, the recommended action generated by the MDP, and the resulting relevant variable are then used as pointers to query a domain knowledge base 


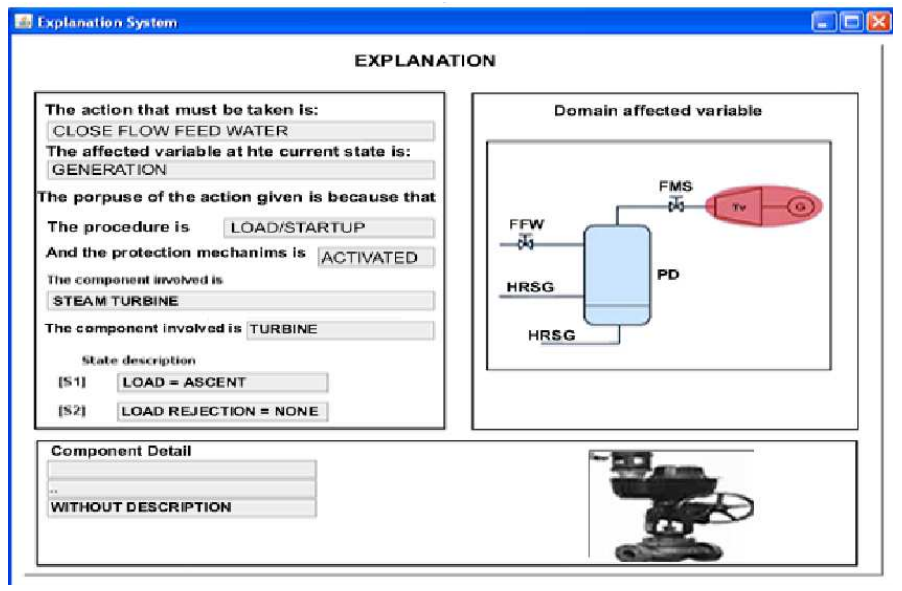

Fig. 2. This template is composed of 3 main parts: (i) the recommended action and the relevant variable in the current situation; (ii) a graphical representation of the process highlighting the relevant variable, and (iii) a verbal explanation.

and extract the relevant information to fill-in the explanation template. A more detailed description of the explanation mecanism can be found in [11].

ASISTO generates an explanation for every user level: novice, intermediate and advanced. Advanced users do not require a well detailed explanation so that they are provided with essencial information only. However, novices might need more specific explanations and a template with more complete information might be displayed. Fig. 2 shows an example of explanation templates for advanced users. In general, the template shows the optimal action on the left hand side, explaining why it is important to perform the recommended action, the component associated to the optimal action, and a brief description of the current plant state. On the right side of the relevant variable there is a diagram of the process associated with the action executed by the user.

When running experiments, operators trainees experienced improvements in their general performance after using the explanation system. We plan to conduct additional user study tests using the explanation module in order to demonstrate that the quality of explanations generated automatically is of a very high standard when compared against those given by a domain expert.

\subsection{Multi-functional Knowledge Based System to Learn, Apply and Consult Procedures}

Lacepro is an adaptive multi-functional knowledge based system for Learning, Applying and Consulting Engineering Procedures [12]. The system achieves its multi-functionality by using a single knowledge representation scheme that facilitates the tutoring, problem solving and consulting tasks, the representation of a user's model and the automatic generation of examples and evaluation prob- 
lems. As shown in Fig. 3, the representation of the domain is exploited by three different knowledge operators (the "Tutor", the "Consultor" and the "Problem Solver"), each of which is in charge of the tasks of tutoring, consulting, and problem solving, respectively. The three knowledge operators consult a user model in order to tailor their explanations to what the user knows and prefers [13]. LacePro uses a machine learning mechanism to learn the rules that result in "good" strategies that are effective for different classes of users [14]. This mechanism is also used to adapt these rules to the preferences of particular users.
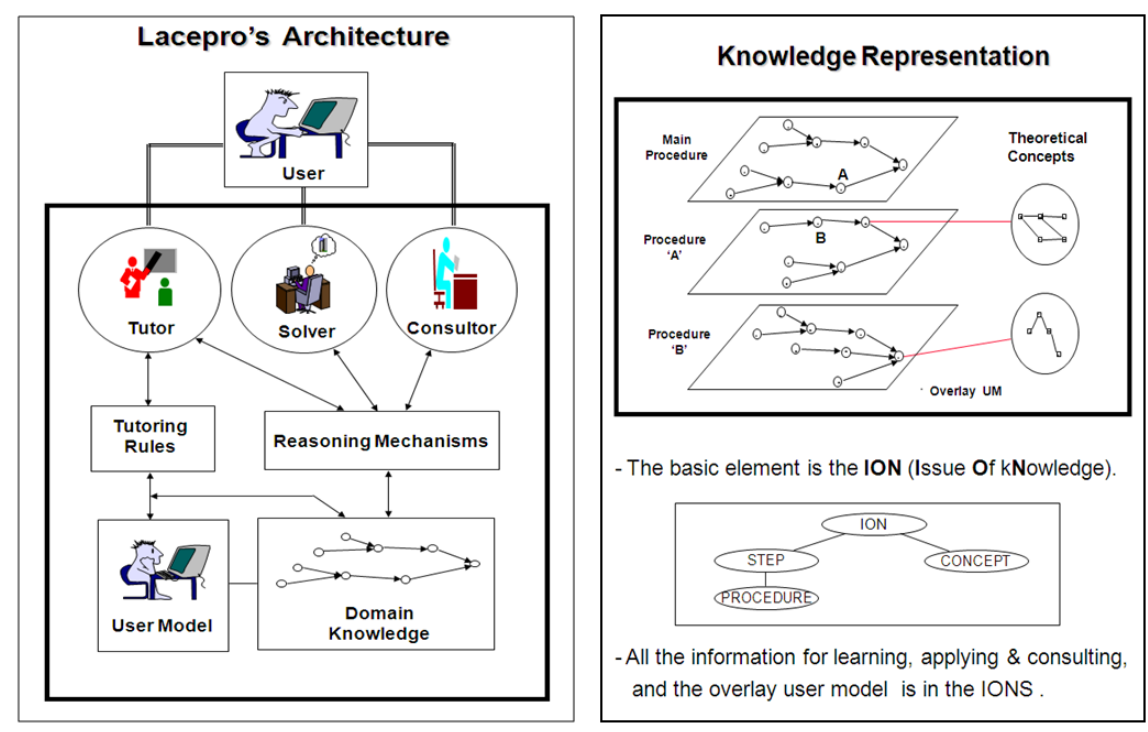

Fig. 3. Lacepro's Architecture and Knowledge Representation. They are the basis for multi-functionality and adaptability to the userss knowledge level and preferences.

In Lacepro, the domain knowledge is represented through a set of goal networks (see Fig. 3). Each node of these networks represents a step within a procedure. A step is a subgoal within a procedure (i.e., the calculation or selection of a parameter or set of parameters through: direct assignment using formulae, production rules, data retrieval from tables, or specialized routines). The links among nodes represent the flow of the procedure. Those concepts required to understand the basis of a step are stored in concept nodes that are linked to the step node.

Lacepro shows that it is possible to develop transparent systems that adapt and evolve continuously as professionals learn and apply procedures as part of their work. 


\subsection{SiDSED: A System for Designing Electrical Distribution Substations}

SiDSED [15] is a system for designing electrical distribution substations that uses different levels of building blocks to simplify the design process and facilitate the estimation of costs of new electrical substations. The building blocks are based on three levels of abstraction; buildings blocks of the highest level are composed from building blocks of lower levels. Each building block has an associated cost obtained from a concepts catalogue with unit prices. The system was developed for power distribution at CFE.

SiDSED was developed in three modules: engineering design module, costs engineering module and visualization module (see Fig. 4).

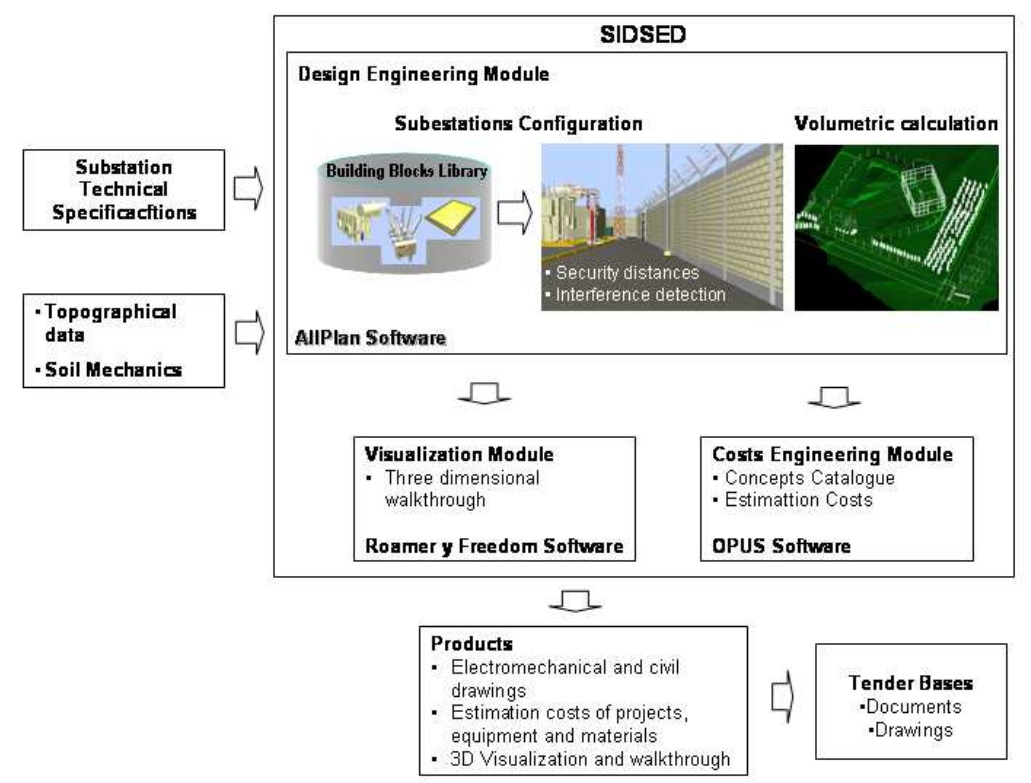

Fig. 4. SIDSED Modules: Engineering design module, costs engineering module and visualization module

In the engineering design module, human designers use the building blocks to design a new electrical substation, taking into account some topographical data. After that, the cost of an electrical substation is estimated with the costs engineering module. Finally, with $3 \mathrm{D}$ visualization and a walkthrough module, designers can make decisions about aspects related with construction, operations, maintenance and training.

Some of the benefits obtained with the use of this type of approaches are related mainly to cost savings through design automation, reduction of construction problems and faster throughput of projects. The building blocks can 
be 3D standards for advanced engineering, automated drawing, data extraction and reusability of designs. We can use it virtual substations for site selection, community and government acceptance, and $3 \mathrm{D}$ visualization and walkthrough can be used to improve construction, commissioning, operations and maintenance. Nowadays, we are training personnel and implementing SIDSED in all CFE's divisions along the country.

\section{Virtual Reality Systems}

\subsection{Virtual Reality Systems for Maintenance Training}

In July 2003, the Virtual Reality Group (GRV) was founded at the IIE. Since then most of the GRVs efforts have been devoted to develop training systems for CFE. The first Virtual Reality (VR) System developed was ALEn3D ( acronym in Spanish for training system for medium live line maintenance). From then on other different training systems were developed, such as: high tension lines, transmission lines, underground lines, and still in development substation maintenance tests (Fig.5 right). They all share the same architecture defined for ALEn3D, which includes three operation modes, namely: learning, practice and evaluation modes (Fig. 5). All these systems are able to keep track of the students progress. The systems are able to remember who used the system, what maintenance procedure was learned, in what step and when the student was using the system, etc. It contains messages for helping students when they make mistakes while learning or practicing.
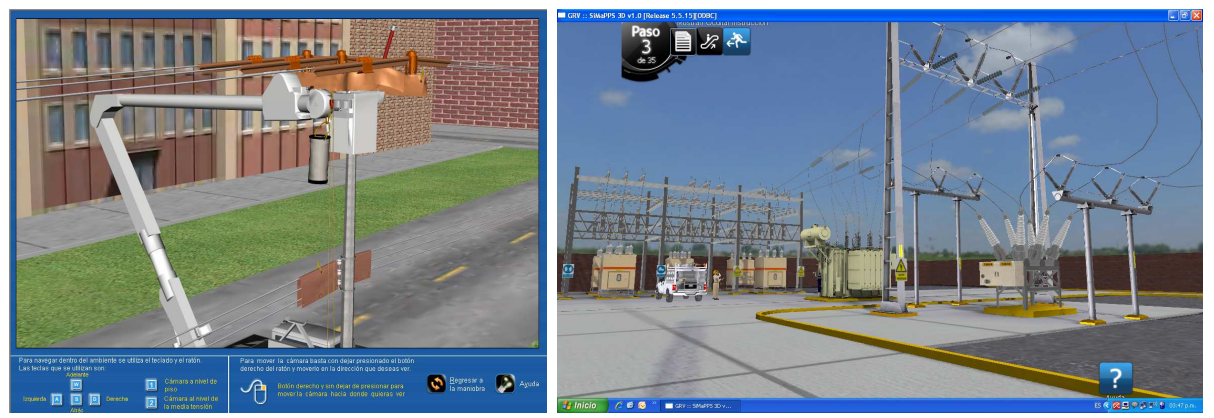

Fig. 5. Learning modes samples: medium tension live line maintenance (left) and substations primary equiment testing (right)

These systems can be used for self learning or presential courses. In the former, all progress made by students is recorded locally in a database, so that students can learn dangerous procedures at their own pace with no risk at all. In the later, all progress is recorded in a server and this information is available for trainers and other company authorities. In this way, learning progress within 
the company can be monitored. The evaluation mode includes two kinds of tests namely, theoretical tests, which are based on multiple choice questions, and practical tests in which a student have to perform a maintenance procedure, based on the same learning/practice 3D scenarios with no help from the system.

Currently, CFE is using successfully these systems for personnel training in all of its 16 distribution divisions located in the whole country. ALEn3D for medium line maintenance training was the winner of the CFE's INNOVA 2008 award. These systems have been developed within the first stage of the VR Roadmap [16]. In this stage, the development of non immersive VR systems [17] is planned. Currently, the GRV is starting the second stage in which the development of immersive systems, the inclusion of augmented reality and collaborative virtual environments are considered.

\subsection{Visor3D Coupled to a Dynamic Simulator}

In this section a prototype of a non-immersive 3D display system coupled to a dynamic real-time full-scope simulator is presented. The name of the prototype is Visor3D, whose aim is to create a virtual world representation of a section of a thermal power plant, with the equipment modeled and textured in detail, so that the user has a realistic sensation of being in the scene. Visor3D shows equipment in 3D and displays, in real time, the recorded status according to the initial condition set by the instructor (from the simulation station), while that one with local control can be infered directly from the simulation session. The main components of the prototype are the simulation system and the display system.

The Simulation System is composed of a set of integrated software components that were adapted to establish communication with Visor3D. A more detailed explanation about the simulator software is available in [18]. In the Display System, the Visor3D is responsible of rendering the virtual environment of the power plant, which consists of static and dynamic equipment (see Fig. 6). The former displays its status in the simulator in real time and can also perform actions such as opening / closing valves through internal parameters. These commands are sent in real time and have influence in the simulation session. The Visor3D also includes an auxiliary operator in the stage, which is represented by an avatar, and supports three types of navigation on the scene: in first person, third person and free form.

Additionally, another component was developed to communicate the simulator and the Visor3D prototype. Its objective is to establish communication with the display system and respond to requests of variables and commands that the user performs from the equipment shown in the virtual environment.

The development of this kind of systems, that include Virtual Reality and dynamic simulation, will help to reinforce the operator training sessions, since he/she will be able to observe in $3 \mathrm{D}$, the effects of his/her operations and phenomena that occur in the processes of power generation that cannot be observed. 


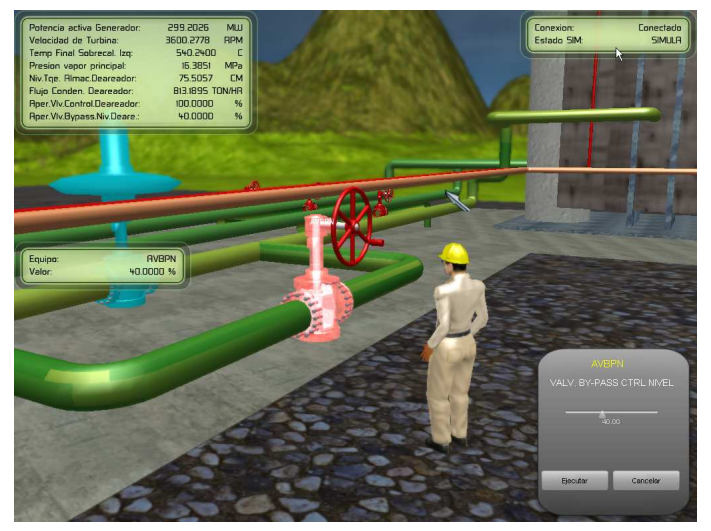

Fig. 6. Display System. Visor3D is responsible of rendering the virtual environment of the power plant

\section{$5 \quad$ Training Simulators}

\subsection{Power Plant Simulators and Expert System for Operator Training}

A power plant simulator is a software system that models the behavior of a real power plant and that can be used for the operators training of such systems. Since it allows the training in special situations that could arise in real life but without endanger persons or real equipment, its principal aim is to provide an integrated training avoiding unnecessary risks .

It has been verified that the operators training of power plants based on training simulators is the most effective way in which an operator familiarizes with the plant at which it will be employed. However, due the high cost of such a training, it is desirable that operators attend these sessions with some previous theoretical / practical knowledge.

The IIE has developed a simulator-expert system [19] aimed to provide a standalone application where operative personnel can practice and be evaluated without the supervision of an instructor. The practice will complement the regular training courses carried out at the training center. This system was developed for the CFE using a $350 \mathrm{MW}$ Coal-Fired power plant simulator (CFS) and a 450MW Combined Cycle power plant simulator (CCS) .

The system is divided into two parts: the definition of an exercise and its execution (see Fig. 7). The exercise is defined by the instructor who stablishes the initial condition of the simulation system, creates questions for the theoretical evaluation, assigns the corresponding multimedia material for the theoretical lessons, and selects the process variables for the simulation evaluation. After that, a tool transforms the exercise into a set of rules to guide/track the trainee operation to be used by an expert system. During the exercise execution, the trainee has a graphical interface to perform a practice. This interface contains the 
main operator's diagrams related to the exercise. The operator may be assisted by the system to indicate what actions to perform to complete the exercise correctly or just to monitor and report a wrong action.

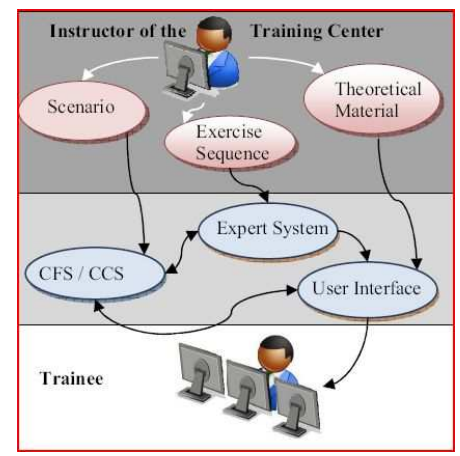

Fig. 7. Simulator-expert system. The system is composed of the definition of an exercise and its execution

\section{Virtual Learning Environments}

\subsection{Virtual Postgraduate Center e-Learning Platform}

The IIE Postgraduate Center (IIE-CP) has developed an e-learning platform called Virtual Postgraduate Center (CPV) [20]. It was implemented using a Learning Management System (LMS) which includes a number of activities and resources for on-line courses. CPV complies with the SCORM standard from Advanced Distributed Learning (ADL), so that SCORM 2004 4th Edition 1.1 learning objects (LO) were developed, which correspond to SCORM compliant teaching material Shareable Content Objects (SCO). In other words, the Content Aggregation Model (CAM - activity tree), the Run-Time Environment Model (RTE- Application Program Interface API between LMS and SCO), the Sequencing Definition Model (S) and the Navegation Model (N) were included into the SCOs using the Tracking Data Model (cmi. - Computer Managed Instruction) and the Sequencing Elements (adl.). The on-line courses structure is in accordance to SCORM and ADL recommendations. Therefore, SCORM content packages are automated by configuring the learning strategy with evaluations and remediation. For tracking the students performance individually and according to his/her perfomance, teaching materials are presented.

Content packages were developed using Author Tools for the e-learning teaching material. An instructional design team and a development team were integrated, and a script was developed to capture the information from instructors about how they want to show their teaching material. 
An LMS offers asynchronous activities, such as discusion forums, and synchronous activities, such as a chat. It also manages the courses, ad hoc configurations, security, accounts and profiles, massive registration and by e-mail, and customizable views and templates. In each course, it registers every interaction and grades, and it generates reports and statistics. At present, CPV has several on-line courses on various topics related to the electric power sector.

As a future work, several new functionalities will be implemented. For instance, the HTML editor (with equations editor and calculator) will be included into the chat (for loading images, videos, audio-narration-music), an on-line author tool (LAMS Learning Activity Management System) for developing teaching material, a virtual classroom (videoconference, whiteboard, chat and desk sharing) and a remote laboratory (VNC-Virtual Network Connection and WebCam) will be integrated, SMS messages (Short Messaging Service) for the students' mobile phones from the LMS will be included, an intelligent tutor system (to integrate an intelligent LMS) will be implemented within the LMS, and a mobile learning tool will be added. In order to develop intelligent learning objects an intelligent sequencing will be implemented for the SCORM content packages.

\section{Conclusions}

A set of eight training and tutoring learning technologies developed at the Electrical Research Institute were presented. It included developments focused on providing different learning styles, considering the student affective state and enabling multi-functionality. Samples of assistant systems, virtual reality systems, power plant real simulators, and virtual center e-learning platforms were also presented.

The developments described here are a good example of how modern technologies provide a great variety of approaches to support the electric power industry.

\section{References}

1. Felder, R., Silverman, L.: Learning and teaching styles in engineering education. Engineering Education 78(7) (1988) 674-681

2. Hernández, Y., Rodríguez, G.: Learning styles theory for intelligent learning environments: Adapting the instruction. In: 3rd International Conference on Computer Supported Education. Volume 1., SciTePress (2011) 456-459

3. Felder, R., A.Soloman, B.: Learning styles and strategies. Technical report, NCSU North Carolina State University (1993)

4. Savic, G., Konjovic, Z.: Learning style based personalization of scorm e-learning courses. In: 7th International Symposium on Intelligent Systems and Informatics, SISY 2009, IEEE (2009) 349-353

5. Ortony, A., Clore, G., Collins, A.: The Cognitive Structure of Emotions. Cambridge University Press (1988)

6. Hernández, Y., Sucar, L.E., Arroyo-Figueroa, G.: Evaluating an affective student model for intelligent learning environments. Iberamia 2010 (2010) 473-482 
7. Costa, P., McCrae, R.: Four ways five factors are basic. Personality and Individual Differences 13(1) (1992)

8. Hernández, Y., Sucar, L.E., Conati, C.: Incorporating an affective behavior model to an intelligent tutor. In Guesgen, H.W., Lane, H.C., eds.: FLAIRS Conference 2009, FLAIRS (2009) 448-453

9. Reyes, A., Ibarguengoytia, P., Elizalde, F., Sánchez, L., Nava, A.: ASISTO: An intelligent assistant system for power plant operation and training. In: 16th Intern. Conf. on Intelligent Systems Application to Power Systems,ISAP 2011, Crete Island, Greece (September 2011)

10. Puterman, M.: Markov Decision Processes. Wiley, New York (1994)

11. Elizalde, F., Sucar, L.E., Luque, M., Diez, J., Reyes, A.: Policy explanation in factored Markov decision processes. In: Proceedings of the 4th European Workshop on Probabilistic Graphical Models (PGM 2008), Hirtshals, Denmark (September 2008) 97-104

12. Buen, P.D., Morales, E., Vadera, S.: A knowledge-based framework for learning, applying and consulting procedures. In C. Frasson, G.G.y.A.L., ed.: Intelligent Tutoring Systems, Germany, Third International Conference, ITS'96, SpringerVerlag (1996) pp. 392-400

13. de Buen, P., Morales, E., Vadera, S.: A collaborative approach to user modeling within a multi-functional architecture. In for Mechanical Sciences, I.C., ed.: CISM Courses and Lectures. Volume No. 407., Italy, Springer-Verlag Wien NewYork (1999) pp. 291-293

14. de Buen, P., Vadera, S., Morales, R.: Machine learning in LacePro multi-functional framework. In: Proceedings of the UM97 Workshop on Machine Learning for User Modeling, Chia Laguna, Sardinia, Italy, Sixth International Conference on User Modeling (June 1997)

15. Pérez, E.I., Rada, J.B., Lima, J.R., Marín, M.M.: Design and costs estimation of electrical substations based on three-dimensional building blocks. 6th International Symposium on Visual Computing (2010)

16. Pérez, M.: Ruta tecnológica de realidad virtual para el sector eléctrico. In Meléndez, A.M., ed.: Komputer Sapiens. Revista de Divulgación de la SMIA.2011. Volume 1., Reforma 113. Col. Palmira. Cuernavaca Mor., México (2011) 11-16

17. Pérez, M., Zabre, E., Islas, E.: Realidad virtual: Un panorama general. In: Boletín IIE:2004, Reforma 113. Col. Palmira. Cuernavaca Mor., México (2004) 39-44

18. Tavira, J., Jimenez, L., Romero, G.: A simulator for training fossil-fuel power plants operators with an hmi based on a multi-window system. International Journal of Computer Aided Engineering and Technology 2010 2(1) (2010) 30-40

19. Tavira, J., Martnez, R., Jiménez, F.: Power plants simulators with an expert system to train and evaluate operators. In: Proceedings of the World Congress on Engineering and Computer Science 2010. Volume Vol II., San Francisco, USA, WCECS 2010 (October 20-22 2010)

20. Jiménez-Fraustro, F.F., García-Hernández, C.F., Aguilar-Figueroa, S.A., Martínez-Ramírez, R.E.: Development of the IIE's virtual postgradute center: Phase i. Technical report, IIE (December 2010) 